correlation between adjacent uncored boreholes. $\mathrm{He}$ stressed the importance of obtaining physical data on the properties of rocks from measurements made in situ, as the information so obtained could be applied in interpreting surface geophysical surveys. The continuous nature of the records also facilitates sampling and the averaging or integration of physical properties over $\boldsymbol{a}_{\mathrm{o}}$ column of strata.

Just as classical studies first concentrated on natural radioactivity and later turned to activation methods, so borehole measurements of natural gamma radiation were followed by neutron techniques. For natural radiation measurements, ionization chambers, Geiger counters and scintillation counters have been used. The latter have a shorter 'active length' and this gives improved discrimination of thin beds. A relatively recent development is the scintillation spectrometer, which is capable of differentiating between the various energy-levels of incoming gamma rays. Since different elements are associated with gamma rays of differing energies, it becomes possible, in some instances, to obtain an indication of the nature of the nuclides responsible for the radioactivity by studying the pulse height distribution.

In neutron methods a neutron source is lowered into the borehole, followed by a detector. Neutrons will be captured by nuclei of the atoms that make up the surrounding rock, and the gamma rays emitted during these reactions can be recorded on a gamma detector. Similarly, if a neutron detector is used the distribution of neutrons in the borehole can be studied. Neutron sources commonly used, for example, radium-beryllium, also emit gamma rays, and it is necessary to shield the detector from the source in both neutron-neutron and neutron-gamma methods. Compton scattering and natural activity of the formation add complications. In gamma- gamma logging, which combines a gamma source and gamma radiation detector, scattered radiation, however, provides information related to formation density. Neutrons lose most of their energy in collisions with hydrogen, and as this element is abundant in both water and oil, neutron logs are important for porosity studies in oil exploration. In mentioning the combination of a neutron source with a scintillation spectrometer as detector, Dr. Bullerwell said that this would seem to offer the possibility of obtaining geochemical data by a geophysical method. A miniature Van de Graaff particle accelerator, 3 in. in diæmeter, $47 \mathrm{in.} \mathrm{long} \mathrm{and} \mathrm{generating}$ $200,000 \mathrm{~V}$., has been used to produce an intense beam of neutrons during borehole experiments in the United States.

Radiometric logging methods have been applied in widely differing fields. Applications to detailed studies of radioactive ore-deposits are usually quite direct and closely controlled by assayed samples. Quantitative comparisons between sedimentary formations in oil-wells or deep structural boreholes, however, are complicated by varying conditions of observations. Calibration of instruments provides little difficulty, but ancillary data must be recorded to permit adequate correction for variations in borehole-diameter, mud-density, cement collars and thickness of casing. In concluding, Dr. Bullerwell stressed that these methods provide basic geophysical information, and he expressed the hope that should the proposal to drill a deep borehole to explore the Mohorovičic discontinuity come to fruition, then the opportunity to obtain a comprehensive series of geophysical logs should not be overlooked.

The chairman closed the meeting after a short informal discussion in which several speakers took part.

S. H. U. BowIF

\title{
CLIMATE, VEGETATION AND LAND UTILIZATION IN THE HUMID TROPICS
}

\begin{abstract}
A T the Ninth Pacific Science Congress, which was held at Bangkok, Thailand, during November 18-December 9, two days were devoted to a symposium on climate, vegetation and land utilization in the humid tropics, in which some eleven sperkers desit with different aspects of these closely related subjects. In addition to papers read by their authors, a few papers were read on behalf of contributors who were not present, and some invited guests, including one of the present writers (P. W. R.), who did not prepare papers, were asked to contribute to the discussions. The convener was Dr. F. R. Fosberg (Pacific Vegetation Project, Washington, D.C.), and the symposium was organized, and its proceedings will be published, with the financial support of Unesco. As so often happens, the time allotted for general discussion proved insufficient; nevertheless, a valuable opportunity was provided for an exchange of ideas between workers in different disciplines which do not come often enough into contact.

At the outset there was the question of definition : What do we mean by the tropics in general and by the humid tropics in particular? Broadly, as Dr. Fosberg said in his opening remarks, the two belts of trade-winds blowing towards the equator and the
\end{abstract}

shifting belt of calms or doldrums are of greatest importance in defining these regions. Dr. David I. Blumenstock (Hawaii), who contributed a paper on the characteristics and distribution of tropical climates, expanded this by reminding the Congress of the special significance of weather or circulation regions, such as the monsoon region and, perhaps surprisingly, the hurricane areas; he regarded the tropical olimatic realm as best defined as the region within which the temperature of the coldest month in the lowlands averages at least $64 \cdot 4^{\circ} \mathrm{F} .\left(18^{\circ} \mathrm{C}\right.$.), with the included upland and mountain areas. In this sense the lowland humid tropics are the frost-free areas of the world, where the unique features are in the illumination and radiation regimes rather than in that of insolation. Dr. Blumenstock considered that radiation is a more important factor than previously believed. In regard to temperature he emphasized the importance of extremes ; in regard to moisture, the significance of dew and the variability of rain through the year.

Dr. C. G. G. J. van Steenis (Leyden) and Dr. Carl Troll (Bonn) dealt, respectively, with the lowland and the mountain vegetation of the tropics. In the course of a very comprehensive review of tropical- 
vegetation types, van Steenis took the discussion away from mathematically defined climatic types to vegetation types related to different phytoclimates. After briefly discussing plant life-forms and the use of individual plant species as climatic indicators, he proposed a system of ten 'fundamental' climatic types of tropical lowland vegetation. This was later criticized by Prof. P. W. Richards as consisting of a mixture of climatic, edaphic and seral types of very unequal importance in the tropics as a whole. Dr. Troll made out the case for six altitudinal zones of tropical mountain climates, again based chiefly on vegetation. He demonstrated the use of thermoisopleth diagrams and stressed the iraportance of frost in determining the altitudinal zones in the tropics.

A trend away from the definition of tropical climatic types in terms solely of a mathematical interpretation of figures, and towards one based on their influence on vegetation and crops appeared in the contributions of Dr. F. Egler (Aton Forest, Connecticut) and Prof. P. Dansereau (Montreal); the former, in fact, stated the case for the geographer's approach (though he did not refer to it as such, but called it 'holism') in suggesting that climate, soil and vegetation must not be regarded, as they sometimes have been in the past, as mutually exclusive fields of study.

The sad death of Dr. R. L. Pendleton and the illness of Dr. D. L. Bramao left the preparation of a statement on tropical soils to Dr. R. Dudal (Food and Agriculture Organization). Although he described his paper as a hurriedly prepared draft and it was not available to the Congress until the symposium was over, his succinct oral presentation conveyed conviction that at last a logical classification of tropical soils was being worked out. Where tests had been made, in Java and Borneo, the ten types in the scheme proposed arrange themselves in a logical sequence related primarily to relief-slope and drainage. The prineiple that the soil types are related to a certain range of land-forms as well as to vegetation was in line with points made by Dr. Egler and later by Dr. Christian.

The whole symposium stressed the need for the survey or observational approach to many of the problems. The huge areas in tropical Australia, Papua and New Guinea surveyed from the air and mappod under his direction lod Dr. C. S. Christian (Commonwealth Scientific and Industrial Research Organization) to ask how best the results may be utilized. He saw that the land must be considered as embracing all factors of importance to man's well-being. Specific areas identifiable by their 'major observable inherent features' (of topography, soil, vegetation and climate) are termed by Christian 'land units' grouped into 'land systems'. These are more or less equivalent, respectively, to the 'stows' and 'tracts' of J. F. Unstead, and because of the other uses of the word 'system' as applied to land, 'tracts' is perhaps a safer word to use.

The cartographic approach to the problems discussed in the symposium was dealt with perticularly by Prof. Henri Gaussen (Toulouse), who exhibited a number of the vegetation maps of France and other countries produced by his laboratory. He suggested the publication of a series of maps of vegetation in the tropics on the scale of $1: 1,000,000$, the only scale on which base maps are generally available. Gaussen's scheme agrees essentially with that advocated by the Commission on World Land Use Survey of the International Geographical Union in mapping the vegetation actually present (that is, without making any theoretical assumptions about 'climexes', etc.), but wheress Grussen uses only eight types of vegetation-four types of forest, savanna, desert, shores and cultivation-the World Survey considered it possible to go further in separating categories of land-cover; it also thought that the interpretation of the pattern found should be made in explanatory memoirs, while Gauseen believes it possible to indicate ecological conditions by colours on the map itself. The case for these two alternative approaches has been argued before on many occasions. The World Land Use Survey wished to make the maps as objective as possible; the facts can be interpreted in more than one way and if, as Gaussen proposes, the ecological factors believed to be responsible are shown on the map itself, a subjective judgment is necessarily introduced. Given the validity of the underlying assumptions, however, the magnificent quality and value of the Gaussen maps will be generally acknowledged.

If the first day of the symposium may be said to have dealt with the fundamental features of man's environment, the contributors on the second day dealt mainly with the effects, direct and indirect, on these features of man himself. The opening spesker, Dr. E. Aubert de la Rüe (Paris), gave a broad review of the rapid disappearance of the natural plant cover in all parts of the tropics, which in the future may be seen only if national parks and nature reserves are established. Dr. Dioscoro S. Rabor (Silliman University, Philippines) in a communicated paper dealing with wild life in the Philippines made the further point that wild life (that is, mammals and birds) depends on the natural vegetation, and as long as that is conserved it, too, is protected.

Dr. Carl Sauer (University of California) in a communicated paper on "Man in the Ecology of Tropical America" accepted as proved (perhaps rather surprisingly) the view that there was formerly a much larger population in the American tropics and argued. for the presence of numerous agricultural tribes even in the forests of Amazoniz. Both he and Dr. Ooi Jin-Bee (University of Malaya), who followed with a paper on the distribution of present-day man in the tropics in a historical and ecological perspective, noted the comparatively simple relationship between human distribution and favourable environmental conditions (such as the wet lowlands suitable for rice in south-east Asia) in the past and the changes consequent on the development of exploitable resources. Dr. Sauer held that in the American tropics European livestock were able to range over the former fields of a decimated sedentary population. Whether this was so or not, it is generally agreed that much sevenna formerly regarded as climax vegetation does not correlate well with either climate or soil and can only be explained by the destruction of tree seedlings during man's annual burning of grass. Tropical grasses are only palateble to stock when young and tender, hence the need to burn off the old tough stems and encourage new growth. A paper from Dr. R. O. Whyte (Food and Agriculture Organization) here reminded the symposium that scientific management of tropical grasslands has scarcely begun, and that a first step in any area is to try to understand the relationship between grassland and the climatic climax vegetation when the biotic factors of grazing and burning are eliminated.

A major current problem in the tropics is undoubtedly the integration of agriculture and forestry. 
A paper from Mr. Colin Marshall (Malaya) emphasized some fundamental truths which are certainly not appreciated by most policy makers in tropical countries at the present day. The increase of population with the spread of Western medical, sanitary and economic systems in tropical countries makes scientific land-use planning and its acceptance by governments and peoples absolutely essential. It is perhaps because scientific forestry - the intelligent management of forested land on a sustained yield basis-has been imposed on the peoples of tropical Asia from outside that in their new-found independence there is an undoubted tendency to regard forest reserves not as an attempt to conserve a valuable resource or to control soil erosion and make good use of land unsuitable for other economic use, but as a restriction on the liberty of the people. The creation of useless wastes in many parts of the world is due to the mistaken concept that forest is simply an impediment to be destroyed in order to free land for grazing and cultivation. Nothing is more important than that forests should be maintained to perform their many functions in a balanced land economy; only land which can be used more effectively in that way should be turned over to cultivation.

This leads on to the question of shifting cultivation, which was dealt with by Dr. Karl Pelzer (Yale University), who, however, wished to replace the term 'shifting cultivation' by 'swidden farming'. It is not wholly bad, he said, as is sometimes maintained. Where it is a deliberate agricultural technique (as with 'bush fallow' in parts of Africa) the cultivator knows the value of rotating his patches of cultivation to maintain soil fertility and can be regarded as conservation-minded. Yet the forester recognizes the extravagance of a system in terms of land, which prevents the regeneration of natural forest or economic timber while maintaining the land almost completely idle for perhaps a dozen years out of fourteen. In exceptional cases, useful quickgrowing trees such as Casuarina are deliberately planted in the fallow period, but normally there can be little doubt that the substitution of some other system or systems is vital and urgent. But what other systems? Almost certainly not the permanent dry-field cultivation of annual plants practised in mid-latitudes. The right use of many upland tropical areas is in perennial, especially tree, crops; while in many lowlands wet rice fields are not only a productive form of cultivation but ensure a well-guarded soil. In other words, agricultural developments must be integrated with physical conditions.

Prof. Dudley Stamp, in a paper on "Land Use in the Humid Tropics : Living Space and Recreation", directed attention to uses of land other than for food production; man can indeed not live by bread alone. The need of land for housing, industry, defence and recreation competes with the need of land for agriculture. In crowded countries where there is difficulty in deciding between alternative uses of land in the national interest, three principles may be applied-that of optimum use, that of multiple use, and that of the elimination of waste land.

In the concluding paper of the symposium the chairman and convener, Dr. F. R. Fosberg (Wash. ington), considered man from an ecologist's point of view. Hitherto, he pointed out, man has behaved as a pioneer species, increasing rapidly in numbers, drastically altering his habitat, and using up the resources on which he depends at a rapid and accelerating rate that definitely places a limit to their duration; in the case of some of them this limit is already being approached. It may be, however, that with the development of the faculty of intelligence man has within his power the choice of behaving either as a pioneer organism, destroving its habitat and consequently soon disappearing from it, or as a climax organism preserving its habitat and learning to live in equilibrium with it. If this is to happen, the sciences of geography and ecology must take the lead in determining how to establish a permanent equilibrium between man and his environment. Ecology must perform, on a scale not heretofore imagined, its function of integrating the data provided by other sciences, including the social sciences. Though the magnitude and difficulty of this task may make it seem impossible, our courage in attacking it may well determine the future of man on earth.

In summing up the symposium, Prof. Dudley Stamp said that every paper led to the same conclusion-with increasing pressure of population there must be conscious planning of land use and resources firmly based on scientific knowledge as well as on an appreciation of the varied needs and desires of human beings. This is particularly true of the humid tropics, where in many parts there are vast resources but fow people, and so still hope of avoiding the worst blunders made in cooler lands. There must be mutual co-operation between planners and users as well as between different users. Our case is hopeless if we continue to regard the forester and agriculturist as enemies or the conservation of fauna and flora as inconsistent with the economic development of resources ; the varied aims, all desirable in themselves, must be co-ordinated into one comprehensive plan.

The first thing that is required is an inventory and appraisal of resources, which should take the form of a factual land-use survey preceding any attempt at interpretation. A few examples of such surveys from the humid tropics are the magnificent reconnaissance maps of Ghana, the recently completed outline survey of the Sudan, the aerial survey of Pakistan, the recently commissioned air survey of Burma, the survey of Samoa carried out by the University of New Zealand, the fine detailed maps of Hong Kong prepared by the University, the detailed maps of Taiwan and, if one may stretch the tropics so far, the superlative detailed maps of Japan. All these follow broadly the recommendations of the Special Commission of the International Geographical Union approved at a meeting sponsored by Unesco in 1950 .

The field covered by the symposium was an immensely wide one, but Prof. Dudley Stamp thought it covered only half the main problem. The other half is the human angle. The whole purpose of planning and rational land utilization is to secure an increased standard of living and a fuller measure of life for the people. What, in fact, do people want? Are our Western concepts of the standard of living the right ones? May not our search for efficiency be destroying values far more worth-while? He mentioned these points to emphasize his belief that the demographer, the sociologist and their many colleagues must carry out studies parallel to those with which the symposium had been concerned. It is difficult to plan unlegs one knows what one is planning for.

L. Dudley Stamp P. W. RIChaRDS 